\title{
Caracterização da diversidade genética entre acessos crioulos de feijão (Phaseolus vulgaris L.) coletados em Santa Catarina por marcadores RAPD
}

\author{
Characterization of the genetic diversity of landraces of common bean (Phaseolus vulgaris L.) \\ collected in Santa Catarina State by RAPD markers
}

\author{
Márcio Fonseca de Carvalho ${ }^{\mathrm{I}}$ Maraisa Crestani ${ }^{\mathrm{I}}$ Francine Lunardi Farias $^{\mathrm{I}}$ \\ Jefferson Luís Meirelles Coimbra ${ }^{\mathrm{I}}$ Amauri Bogo ${ }^{\mathrm{I}}$ Altamir Frederico Guidolin ${ }^{{ }^{*}}$
}

\section{RESUMO}

O conhecimento da diversidade genética, por meio da dissimilaridade entre os genótipos, permite a organização, a amostragem e a utilização eficiente do germoplasma em programas de melhoramento genético. O objetivo deste trabalho foi estimar a dissimilaridade entre acessos crioulos de feijão coletados no Estado de Santa Catarina, integrantes do banco ativo de germoplasma de feijão da UDESC e de três cultivares comerciais ("Pérola”, “SCS 202-Guará” e "BRS Valente"), por meio de marcadores moleculares RAPD. Foram utilizados 21 iniciadores decâmeros que permitiram a visualização de 96 bandas, sendo que 41 (42,7\%) apresentaram polimorfismo entre os acessos estudados, resultando em bandas entre 650 e 2000pb. A dissimilaridade foi calculada utilizando-se o coeficiente de Sorensen-Dice e o agrupamento foi realizado pelo método UPGMA. Os acessos foram separados em dois grupos principais, com dissimilaridade relativamente alta, quando comparada com a dissimilaridade observada dentro de cada grupo. Os dois grupos formados indicam os centros de domesticação, Mesoamericano ou Andino, dos acessos analisados. A dissimilaridade entre as cultivares avaliadas ("SCS 202-Guará", "BRS Valente” $e$ "Pérola") é baixa $(0,15)$, se comparada com a dissimilaridade entre os demais acessos do banco de germoplasma $(0,65)$. A menor dissimilaridade entre os acessos estudados (BAF63 $e$ BAF04) foi de 0,02. A inexistência de acessos repetidos reforça a necessidade de novas coletas de germoplasma, o que resultará em um banco de germoplasma de feijão mais representativo da variabilidade genética remanescente em Santa Catarina.

Palavras-chave: Phaseolus vulgaris L., germoplasma, RAPD, dissimilaridade.

\section{ABSTRACT}

The knowledge of the genetic diversity through the divergence among the genotypes allows the organization of the germplasm, sampling and efficient utilization in breeding programs. The objective of this study was to analyze the dissimilarity among germplasm collected in Santa Catarina State, stored in UDESC germplasm active bank of common bean, and of three cultivars ('Pérola', 'SCS 202-Guará' $e$ 'BRS Valente'), using RAPD markers. 21 decamer-primers that allowed the visualization of 96 bands were used, and 41 (42.7\%) presented polymorphism among the studied accesses, resulting in a band range of 650 to 2000pb. The dissimilarity was calculated using the Sorensen-Dice coefficient and the grouping analyses were derived from UPGMA. The accesses were separated in two main groups, with wide dissimilarity when compared with the divergence inside each group. These two groups indicate the possible center of domestication, MiddleAmerican or Andean, of the accesses in this study. The dissimilarity among the cultivars evaluated ('SCS 202-Guará', 'BRS Valente' $e$ 'Pérola') was small (0.15), if compared with the divergence among the accesses of the germplasm bank (0.65). The smaller dissimilarity among the studied accesses (BAF63 and BAF04) was 0.02. The results reinforce the need of new collection expeditions, which will increase the representation of the genetic variability of the remaining bean landraces in Santa Catarina State.

Key words: Phaseolus vulgaris L., germplasm, RAPD, dissimilarity.

\section{INTRODUÇÃO}

O feijão (Phaseolus vulgaris L.) é uma das culturas mais difundidas no mundo, representando metade dos grãos de leguminosas consumidos, sendo uma das principais fontes calórico-protéica para cerca de 500 milhões de pessoas, predominantemente das

'Programa de Pós-graduação em Produção Vegetal, Departamento de Agronomia, Centro de Ciências Agroveterinárias, Universidade do Estado de Santa Catarina (UDESC). Av. Camões, 2090, 88520-000, Lages, SC, Brasil. E-mail: guidolin@cav.udesc.br. * Autor para correspondência. 
regiões menos desenvolvidas do planeta (SCHOONHOVEN \& VOYSEST, 1991). Ele é cultivado tradicionalmente em pequenas propriedades pouco tecnificadas, mas vem passando por grandes transformações. A região Sul do Brasil, nos últimos 15 anos, reduziu a área colhida (RS -39\%, SC -66\% e PR $16 \%$ ) e aumentou o rendimento de grãos colhidos (RS $+32 \%$, SC $+53 \%$ e PR $+111 \%$ ), caracterizando um aumento do nível tecnológico dos agricultores, com destaque especial à substituição da semente própria, de material não-melhorado (landraces), por poucas cultivares comerciais (IBGE, 2006; ICEPA 2006). Este comportamento conduz ao aumento da erosão genética na cultura do feijão, fazendo-se necessário um trabalho de coleta, caracterização e manutenção da diversidade genética ainda disponível junto aos agricultores. A manutenção desta variabilidade genética pode ser de grande valor pela probabilidade de conterem alelos que conferem adaptação local, resistência à doenças e tolerância às principais adversidades edafoclimáticas da região.

A variabilidade genética do feijão está associada a dois centros distintos de diversidade, conhecidos por pool gênico Mesoamericano e pool gênico Andino. Os cultivares pertencentes a cada um destes pools gênicos têm sido subdivididos em 12 pools gênicos ou em seis raças por meio de análises morfológicas, agronômicas e bioquímicas (SCHOONHOVEN \& VOYSEST, 1991). A correlação entre os grupos de dissimilaridade com o centro de origem Mesoamericano ou Andino e suas respectivas raças tem sido realizada por meio da classificação das proteínas de reserva da semente do feijão (faseolinas), associando aos marcadores morfológicos, isoenzimáticos e de DNA (BEEBE et al., 2001).

Ao avaliar a diversidade genética entre acessos de feijão, com o uso de marcadores moleculares, JOHNS et al. (1997), DUARTE et al. (1999), FRANCO et al. (2001) e EMYGDIO et al. (2003b) constataram a divisão em dois grandes grupos. Segundo BEEBE et al. (2001), a separação do feijão em dois grandes grupos está fortemente correlacionada aos grupos de origem Andino e Mesoamericano. O uso de marcadores RAPD têm sido eficiente na separação de acessos de feijão quanto aos grupos de origem Andino e Mesoamericano (VASCONCELOS et al., 1996).

Para a utilização adequada dos recursos genéticos de um banco de germoplasma, é fundamental que se conheça a diversidade genética entre os acessos disponíveis. Quanto maior a diversidade genética entre os acessos disponíveis, maior será a probabilidade de se encontrar alelos de interesse. O conhecimento da diversidade genética também permite a escolha do genótipo adequado e dos métodos de seleção a serem utilizados, em função dos recursos disponíveis e da distância genética entre os genótipos a serem recombinados, conforme os objetivos do programa de melhoramento (SINGH, 2001). Por outro lado, o conhecimento desta diversidade genética, por meio da dissimilaridade entre os genótipos de interesse, permite maior eficiência na organização do germoplasma coletado e nas amostragens (NIENHUIS et al., 1995).

$\mathrm{Na}$ avaliação da diversidade genética, destacam-se os marcadores moleculares, pois, quando comparados com outros tipos de marcadores, apresentam maior número de locos polimórficos, o que permite a distinção entre acessos, mesmo com morfologia similar. Algumas complicações, como o efeito ambiental, tempo necessário para avaliações, herança poligênica, entre outras, podem ser evitadas pelo uso da análise direta do genótipo por meio de marcadores moleculares de DNA. Entre estes, o RAPD merece destaque pelo baixo custo, pela rapidez e pela facilidade de execução, especialmente quando se trabalha com grande número de amostras, como no caso de um banco de germoplasma (ZIMMER et al., 2005).

O objetivo deste trabalho foi avaliar a diversidade genética entre acessos do banco ativo de germoplasma de feijão da UDESC (BAF), coletados no Estado de Santa Catarina (SC), e três genótipos comerciais (SCS 202-Guará, BRS Valente e Pérola), por meio de marcadores moleculares RAPD.

\section{MATERIAL E MÉTODOS}

O trabalho foi conduzido em Lages, SC. Os genótipos utilizados foram três cultivares e quarenta acessos de feijão (Phaseolus vulgaris L.) do banco ativo de germoplasma da UDESC, conduzidos por quatro gerações de autofecundação (Tabela 1). A semeadura dos genótipos estudados foi em telado, em vasos com substrato Plantimax ${ }^{\circledR}$. Após a emissão do primeiro trifólio, foram colhidas folhas jovens e sadias, as quais foram imediatamente imersas em nitrogênio líquido e posteriormente submetidas à liofilização. As folhas liofilizadas foram armazenadas a $-80^{\circ} \mathrm{C}$, em frascos hermeticamente fechados. As folhas liofilizadas foram maceradas em um gral de porcelana, em presença de nitrogênio líquido. Para a extração do DNA, foram utilizadas 30mg de folhas maceradas, conforme o protocolo descrito por DOYLE \& DOYLE (1990). A concentração de DNA foi determinada em gel de agarose $1 \%$.

Para as reações de amplificação (PCR), foram utilizados oligonucleotídeos (iniciadores) de dez bases. As reações de RAPD foram feitas para um volume final de 
Tabela 1 - Cultivares e acessos do banco de germoplasma de feijão da UDESC (BAF) utilizados para análise de dissimilaridade, nome comum, procedência (local de coleta), coloração do tegumento (CT) e peso de 100 sementes (PCS). Lages, 2005.

\begin{tabular}{|c|c|c|c|c|}
\hline BAF & Nome comum & Procedência & $\mathrm{CT}$ & PCS \\
\hline 01 & Preto Serrado 5F 3P & Ponte Serrada & Preta & 36,4 \\
\hline 03 & Manchinha & Palmitos & Creme/vermelho & 27,2 \\
\hline 04 & Amendoim Lages & Lages & Vermelho & 37,3 \\
\hline 07 & Preto Lages & Lages & Preto & 17,2 \\
\hline 10 & Mourinho & Palmitos & Roxo (mouro) & 20,5 \\
\hline 13 & Taquara & Caxambú do Sul & Preto & 21,0 \\
\hline 19 & Minas SC & Palmitos & Vermelho & 19,4 \\
\hline 20 & Minas Vermelho Manchado & Palmitos & Vermelho & 17,9 \\
\hline 23 & Preto Chapecó (10F 10 P) & Chapecó & Preto & 35,9 \\
\hline 25 & Minas Preto & Palmitos & Preto & 15,8 \\
\hline 28 & Vermelho Saudades & Saudades & Vermelho & 45,5 \\
\hline 29 & V ermelho Ituporanga & Ituporanga & Vermelho & 37,7 \\
\hline 32 & Feijão Cavalo & Coronel Freita & Branco/preto & 43,8 \\
\hline 33 & Feijão Cavalo & Concórdia & Preto & 34,7 \\
\hline 36 & Rasga $\mathrm{Cu}$ & São José do Cerrito & Preto & 22,2 \\
\hline 39 & Sem denominação & Bom Jardim da Serra & Creme/vermelho & 36,0 \\
\hline 40 & Feijão Vagem Roxa & Capão Alto & Preto & 20,3 \\
\hline 41 & Rosinha & Bom Jardim da Serra & Preto & 21,8 \\
\hline 42 & Feijão V agem Branca & Capão Alto & Preto & 20,2 \\
\hline 43 & Olho de Pomba & Capão Alto & Vermelho/branco & 38,4 \\
\hline 44 & Vermelho & Capão Alto & Vermelho & 21,4 \\
\hline 45 & Carioca & Capão Alto & Carioca & 26,6 \\
\hline 46 & Sem denominação & Lages & Preto & 37,9 \\
\hline 47 & Preto (precoce) & Piratuba & Preto & 38,2 \\
\hline 50 & Carioca Brilhante & Lebon Regis & Carioca & 22,8 \\
\hline 51 & Roxo & Cunha Porá & Roxo (mouro) & 36,4 \\
\hline 53 & Enxofre & Cunha Porá & Amarelo & 42,9 \\
\hline 54 & Olho de Pombo & Cunha Porá & Branco/Vermelho & 35,2 \\
\hline 55 & Preto & Cunha Porá & Preto & 19,0 \\
\hline 56 & Preto Taquara & Cunha Porá & Preto & 20,3 \\
\hline 57 & Preto & Cunha Porá & Preto & 35,0 \\
\hline 58 & Vermelho & Cunha Porá & Vermelho & 35,8 \\
\hline 59 & Barrosinho & Bom Jardim da Serra & Rosa & 17,0 \\
\hline 60 & Preto 60 dias & Lebon Regis & Preto & 19,7 \\
\hline 61 & Sete semanas & Painel & Vermelho & 34,7 \\
\hline 62 & Vermelho Miúdo & São Joaquim & Vermelho & 24,1 \\
\hline 63 & Vermelho graúdo & São Joaquim & Vermelho & 36,1 \\
\hline 64 & Amarelão de Campo Belo & Campo Belo do Sul & Amarelo & 35,6 \\
\hline 65 & Mouro & Lebon Regis & Roxo (mouro) & 21,9 \\
\hline 93 & Bolinha Rajado & Bom Retiro & Amarelo & 19,4 \\
\hline- & Cultivar "Pérola" & Lages & Carioca & 26,8 \\
\hline- & Cultivar "SCS 202-Guará" & Lages & Carioca & 27,1 \\
\hline- & Cultivar "BRS Valente" & Lages & Preto & 23,9 \\
\hline
\end{tabular}

$25 \mathrm{~mL}$ contendo tampão da enzima sem $\mathrm{Mg}, 1,5 \mathrm{mMMgCl}_{2}$, $0,2 \mathrm{mM}$ de cada nucleotídeo, $0,4 \mu \mathrm{M}$ do iniciador, $25 \mathrm{ng}$ de DNA e água ultra pura. Inicialmente foram testados 33 iniciadores, sendo que 21 foram selecionados para a realização deste trabalho (Tabela 2), por apresentarem amplificação, qualidade e repetibilidade nos testes realizados. A qualidade e a repetibilidade das reações foi avaliada em três acessos escolhidos aleatoriamente, utilizando-se três repetições. Foram utilizadas as mesmas condições das reações de validação (desde o lote da enzima até a água utilizada) para todos os demais acessos e cultivares, que foram repetidas uma vez.

Ciência Rural, v.38, n.6, set, 2008. 
Tabela 2 - Iniciadores decâmeros utilizados para análise de dissimilaridade.

\begin{tabular}{cc}
\hline Iniciador $\left(5^{\prime}-3^{\prime}\right)$ & Denominação do iniciador ${ }^{*}$ \\
\hline GAGCCCTCCA & G-03 \\
CTGAGACGGA & G-05 \\
GAATCGGCCA & H-18 \\
AAGGCGGCAG & I-06 \\
GGGACGTTGG & M-12 \\
GAGACGCACA & N-06 \\
TTAGCGCCCC & AA-03 \\
GAGGGACCTC & AM-04 \\
ACTGGGTCGG & AW-09 \\
GTGACATGCC & E-04 \\
GGAAGCTTGG & F-10 \\
ACGCGCATGT & H-12 \\
GACGCCACAC & H-13 \\
GACTGCACAC & L-04 \\
AGTGCGCTGA & Q-04 \\
GGCTGCAATG & Y-04 \\
GGAGCCTCAG & X-11 \\
GGACGCTTCA & Q-14 \\
TGGACCGGTG & C-08 \\
ACGCACAACC & E-15 \\
GGCAGGCTGT &
\end{tabular}

* Nomenclatura dos iniciadores decâmeros conforme Operon Technologies Inc., Alameda CA, USA, 1999.

As reações foram realizadas em termociclador (Techne, modelo Genius), programado para realizar três ciclos a $94^{\circ} \mathrm{C}$ por um minuto, $35^{\circ} \mathrm{C}$ por um minuto e $72^{\circ} \mathrm{C}$ por dois minutos. Depois desses ciclos iniciais, as reações foram submetidas a 34 ciclos de 10 segundos a $94^{\circ} \mathrm{C}, 20$ segundos a $40^{\circ} \mathrm{C}$ e 2 minutos a $72^{\circ} \mathrm{C}$. Ao final, realizou-se extensão de cinco minutos a $72^{\circ} \mathrm{C}$. O produto das reações foi submetido à eletroforese em gel de agarose $1,4 \%$. O padrão de tamanho de fragmentos utilizado foi de 0,1 a 12 kilobases. Após a eletroforese os géis foram fotografados sob luz ultravioleta.

Para o cálculo da diversidade genética, utilizou-se o coeficiente de dissimilaridade de SorensenDice por ser, segundo EMYGDIO et al. (2003a), o mais adequado para estudo de diversidade genética em feijão analisado por meio de marcadores RAPD. Com base na matriz de dissimilaridade genética, foi construído um dendrograma utilizando-se o método de agrupamento da distância aritmética média - UPGMA (DIAS, 1998).

\section{RESULTADOS E DISCUSSÃO}

Os 21 iniciadores utilizados (Tabela 2) permitiram a visualização de 96 bandas, o que resultou em média 4,6 bandas por iniciador. Das 96 bandas, 41 apresentaram polimorfismo entre os acessos estudados, representando $42,7 \%$ de bandas polimórficas. A faixa de tamanhos de fragmentos foi de 650 a 2000pb.

Observando-se o dendrograma (Figura 1), constata-se primeiramente a separação dos acessos em dois grupos maiores, um compreendido entre o BAF03 e o BAF62 (21 acessos e os três genótipos comerciais), denominado grupo 1 e o segundo grupo compreendido pelos acessos entre o BAF01 e o BAF54 (19 acessos), denominado grupo 2, com um índice médio de dissimilaridade de 0,65 entre os grupos.

As evidências observadas neste trabalho reforçam a tese de que os marcadores RAPD separam os genótipos em dois grupos, os quais indicam o grupo 1 como acessos de origem Mesoamericana e o grupo 2 como acessos de origem Andina. O primeiro fator indicativo de o grupo 1 ser Mesoamericano é a presença de genótipos cultivados ("SCS 202-Guará", "Pérola" e "BRS Valente") e de acessos de feijão carioca (BAF45 e BAF50), pois a base genética do melhoramento de feijão no Brasil são os acessos Mesoamericanos. Além disso em trabalhos de caracterização do centro de domesticação, realizada por GEPTS et al. (1988), as cultivares cariocas foram também caracterizadas como mesoamericanas. Um segundo fator é a presença de acessos com faseolina tipo S (BAF 07, BAF 45, BAF 60 e BAF 62) no grupo 1 e acessos com faseolina do tipo T (BAF 39, BAF 47 BAF 57 e BAF 58) no grupo 2 (PEREIRA et al., 2006). A variabilidade observada dentro dos dois grupos foi relativamente restrita, se comparada à encontrada entre os dois grupos, mas suficiente para descartar a hipótese de haver um grande número de acessos repetidos no banco de germoplasma. Esta variabilidade entre os acessos, entendida como restrita, é bem menor entre as cultivares estudadas, evidenciando o potencial dos acessos estudados como fonte de variabilidade genética em cruzamentos, após criteriosa avaliação agronômica.

A maior dissimilaridade encontrada no grupo 1 foi de 0,37 e no grupo 2 foi de 0,27 , enquanto que a maior dissimilaridade encontrada entre as três cultivares estudadas foi de 0,15 . Os acessos BAF63 e BAF04 apresentaram a menor dissimilaridade $(0,02)$, os quais se apresentam como possíveis genótipos de origem comum ou duplicados, juntamente com acesso BAF46, que apresenta baixo índice de dissimilaridade $(0,03)$. Outros dois materiais muito próximos entre si são os acessos BAF47 e BAF57, com dissimilaridade de 0,04. A menor dissimilaridade observada no grupo 1 foi entre o acesso BAF45 e a cultivar "SCS 202-Guará" $(0,05)$. Os acessos BAF07 e BAF13 apresentaram a 


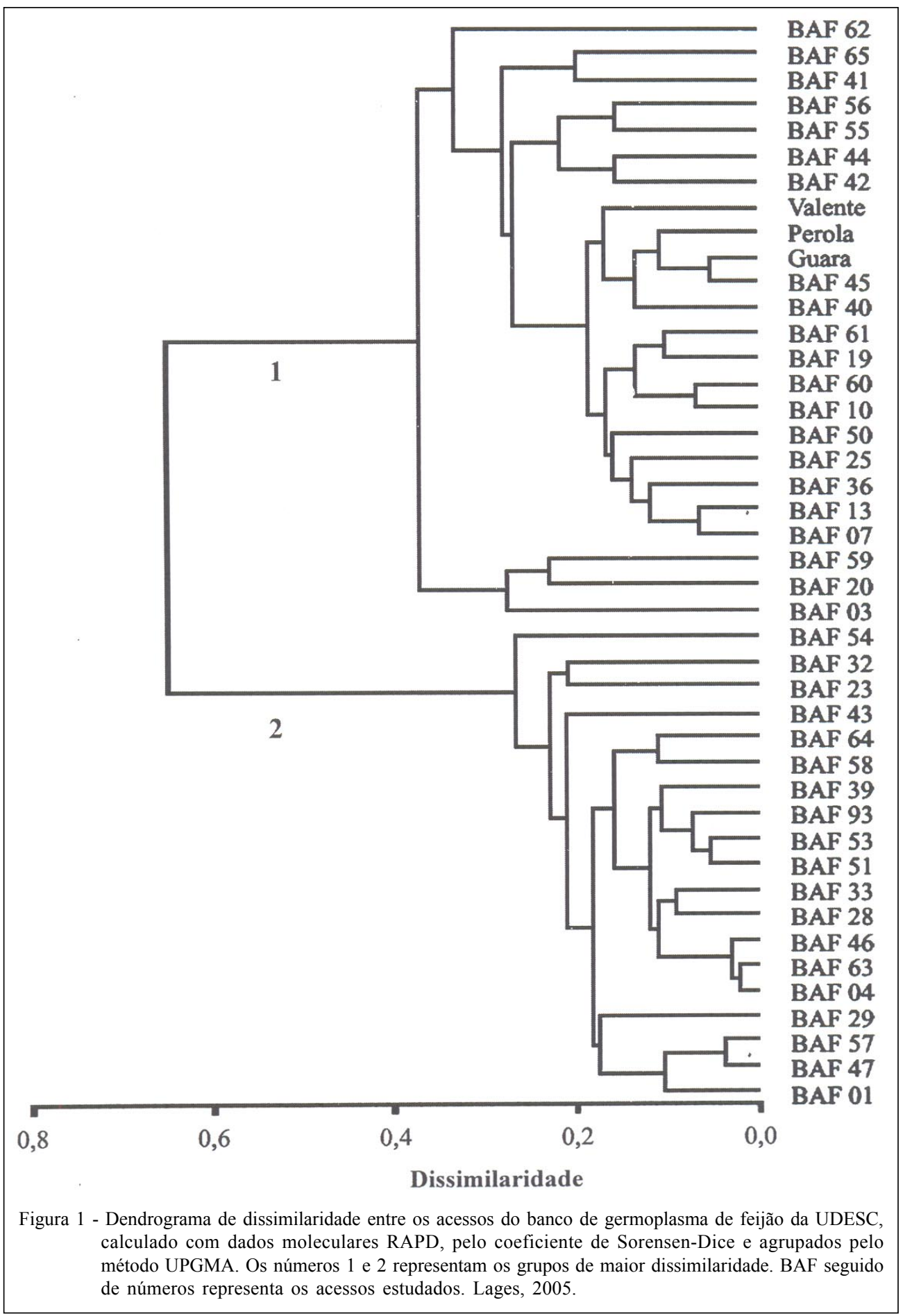

menor dissimilaridade no grupo 1, quando desconsideradas as cultivares. O acesso BAF62 apresentou-se como o mais divergente do grupo 1, com 0,33 de dissimilaridade para com os demais acessos do mesmo grupo. Já no grupo 2 o acesso BAF54 demonstrou a maior dissimilaridade $(0,27)$. A inexistência de um grande número de acessos repetidos é um forte indicativo de que as coletas realizadas ainda não são representativas da variabilidade genética disponível junto aos agricultores de Santa Catarina. Isso reforça a necessidade de novas coletas de germoplasma, bem como a caracterização dos demais acessos quanto ao tipo de faseolina. A caracterização desses acessos possibilitará a identificação das raças de feijão, pois 
durante a domesticação do feijão apenas uma pequena fração das populações de feijão selvagem contribuíram para a formação do pool gênico cultivado. Segundo SINGH (2001), este fato aliado às estritas exigências comerciais, ao uso limitado de germoplasma exótico e às estratégias conservadoras utilizadas pelos melhoristas são os principais fatores responsáveis pela estreita base genética dos cultivares comerciais. Os programas de melhoramento de feijão no Brasil utilizam principalmente o germoplasma Mesoamericano, havendo necessidade de ênfase à introgressão do germoplasma Andino nos cultivares comerciais desta espécie no país, a exemplo de outros países tropicais (GEPTS et al., 1988). A dissimilaridade observada entre as cultivares comerciais estudadas reforça a necessidade de introgressão de germoplasma nos programas de melhoramento genético de feijão.

Os resultados obtidos permitem identificar os acessos com maior e menor dissimilaridade. Ambas tornam-se importantes dependendo dos objetivos e das metodologias empregadas no melhoramento genético. A presença de baixa variabilidade encontrada dentro de cada grupo (Figura 1), quando utilizada em conjunto com características agronômicas e adaptativas dos acessos, pode ser importante para trabalhos de melhoramento que objetivem a transferência de uma ou de poucas características existente nos acessos, para um genótipo cultivado. A maior dissimilaridade é importante em trabalhos em que o cruzamento objetiva a recombinação das características dos genitores, além de promover maior segregação num programa de melhoramento (FRANCO et al., 1997), aumentando a possibilidade de selecionar indivíduos superiores nas gerações segregantes. Ao se selecionar genitores muito distantes geneticamente, um destes apresentará baixa adaptação à região de destino para o cultivo, devendo-se, portanto, reduzir a contribuição genética do genitor não-adaptado por meio de retrocruzamentos com o genitor mais adaptado. É importante ressaltar que os marcadores RAPD, por apresentarem distribuição ao acaso no genoma, medem uma dissimilaridade que não está, necessariamente, ligada a características morfológicas ou de interesse agronômico. Desse modo, a magnitude das diferenças de dissimilaridade, observadas entre os genótipos, pode não refletir de maneira direta a magnitude das diferenças agronômicas, fazendo-se necessária a avaliação agronômica destes genótipos antes de sua utilização pelo melhorista.

A baixa variabilidade dentro de cada grupo pode atuar como fator limitante para trabalhos de melhoramento de feijão visando a recombinação de características dos genitores. Alguns programas de melhoramento que visam o aumento da capacidade produtiva do feijão têm tido resultados insatisfatórios, devido ao emprego, por parte dos melhoristas, de hibridações com genitores do mesmo conjunto gênico. Com a possibilidade de cruzamento de genótipos de diferentes conjuntos gênicos, poder-se-ia avançar na produtividade desta espécie.

\section{CONCLUSÕES}

A baixa dissimilaridade entre as cultivares $(0,15)$, quando comparada com a dissimilaridade entre os acessos coletados em Santa Catarina $(0,65)$, demonstra a importância da coleta e manutenção de germoplasma de feijão. Há necessidade de novas coletas de germoplasma de feijão no Estado de Santa Catarina.

\section{AGRADECIMENTOS}

À Fundação de Apoio à Pesquisa Científica e Tecnológica do Estado de Santa Catarina (FAPESC), pelo financiamento ao projeto, à Coordenação de Aperfeiçoamento de Pessoal de Nível Superior (CAPES), pela bolsa de mestrado, e à Estação Experimental de Lages (EPAGRI), pelo Laboratório de Biotecnologia utilizado nas análises.

\section{REFERÊNCIAS}

BEEBE, S. et al. Diversity and origin of Andean landraces of common bean. Crop Science, Madison, v.41, n.3, p.854862,2001 .

DIAS, L.A.S. Análises multidimensionais. In: ALFENAS, A.C. Eletroforese de isoenzimas e proteínas afins Fundamentos e aplicações em plantas e microrganismos. Viçosa: UFV, 1998. Cap.9, p.405-476.

DOYLE, J.J.; DOYLE, J.L. Isolation of plant DNA from fresh tissue. Focus, Ithaca, v.12, n.1, p.13-15, 1990.

DUARTE, J.M. et al. Genetic divergence among common bean cultivars from different races based on RAPD markers. Genetics and Molecular Biology, Ribeirão Preto, v.22, n.3, p.419-426, 1999.

EMYGDIO, B.M. et al. Eficiência de coeficientes de similaridade em genótipos de feijão mediante marcadores RAPD. Pesquisa Agropecuária Brasileira, Brasília, v.38, n.2, p.243-250, $2003 a$

EMYGDIO, B.M. et al. Diversidade genética em cultivares locais e comerciais de feijão baseada em marcadores RAPD. Pesquisa Agropecuária Brasileira, Brasília, v.38, n.10, p.1165-1171, 2003b.

FRANCO, M.C. et al. Caracterização da diversidade genética em feijão por meio de marcadores RAPD. Pesquisa Agropecuária Brasileira, Brasília, v.36, n.2, p.381-385, 2001. 
GEPTS P. et al. Dissemination pathways of common bean (Phaseolus vulgaris L., Fabaceae) deduced from phaseolin electrophoretic variability: I. The Americas. Economic Botany, New York, v.42, p.73-85, 1988.

ICEPA. Síntese Anual da Agricultura de Santa Catarina 2004-2005. Capturado em 17 junho de 2006. Online. Disponível na Internet http://www.icepa.com.br.

IBGE. Levantamento Sistemático da Produção Agrícola. Capturado em 17 junho de 2006. Online. Disponível na Internet http://www.ibge.gov.br.

JOHNS, M.A. et al. Gene pool classification of common bean landraces from Chile based on RAPD and morphological data. Crop Science, Madison, v.37, p.605-613, 1997.

NIENHUIS, J. et al. Genetic relationships among cultivars and landraces of lima bean (Phaseolus lanatus L.) as measured by RAPD markers. Journal of the America Society for Horticultural Science, Alexandria, v.120, n.2, p.300-306, 1995.
PEREIRA, T. et al. Variabilidade genética em acessos de feijão (Phaseolus vulgaris L.) associada ao perfil total de proteínas de reserva. In: CONGRESSO BRASILEIRO DE GENÉTICA, 52., 2006, Foz do Iguaçu, PR. Anais... Foz do Ribeirão Preto: SBG, 2006. p.962. 1453 p.

SCHOONHOVEN, A.V.; VOYSEST, O. Common beans: research for crop improvement. Cali: CIAT; CAB International, 1991. 980p.

SINGH, S.P. Broadening the genetic base of common bean cultivars: a review. Crop Science, Madison, v.41, n.6, p.1659$1675,2001$.

VASCONCELOS, M.J.V. et al. Genetic diversity of the common bean Phaseolus vulgaris L. determined by DNA - based molecular markers. Brazilian Journal of Genetics, Ribeirão Preto, v.19, p.447-451, 1996.

ZIMMER, P.D. et al. Ferramentas da biotecnologia no melhoramento genético vegetal. Pelotas: UFPel, 2005. $158 \mathrm{p}$. 